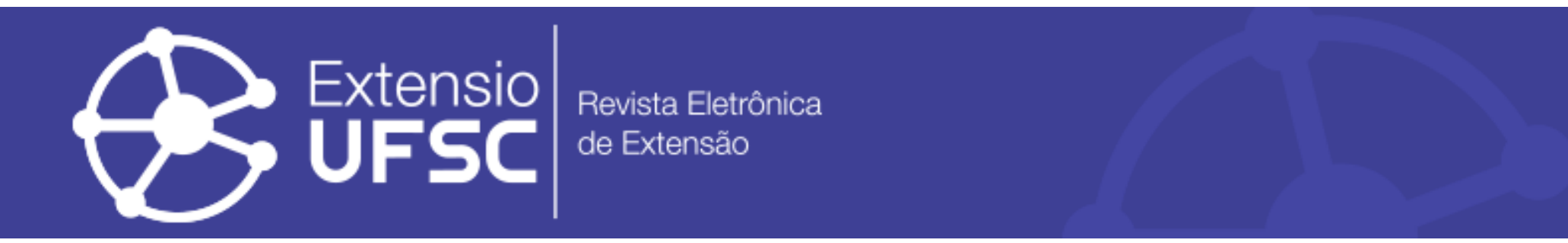

\title{
APLICAÇÃO DA EXTENSÃO COMO ELO ENTRE A PESQUISA E O ENSINO UNIVERSITÁRIO ATRAVÉS DO CONGRESSO ENSUS
}

\author{
Lisiane Ilha Librelotto \\ Universidade Federal de Santa Catarina \\ lisiane.librelotto@ufsc.br \\ Paulo Cesar Machado Ferroli \\ Universidade Federal de Santa Catarina \\ ferroli@cce.ufsc.br
}

\section{Resumo}

O ENSUS - Encontro de Sustentabilidade em Projeto é um evento anual, com duração de três dias, que acontece na cidade de Florianópolis (SC), no campus da UFSC - Universidade Federal de Santa Catarina. É a principal atividade de um programa de extensão universitária que engloba diversas outras atividades, cujo objetivo principal é promover a disseminação do conhecimento gerado em pesquisas com a temática da sustentabilidade aplicada em projetos, focada em engenharia, arquitetura e design. Tem por público-alvo, estudantes de graduação e pós-graduação, além de pesquisadores e profissionais atuantes destas áreas. É por essência interdisciplinar, fomentando a troca de experiências teóricas e práticas entre universidades brasileiras e estrangeiras. Teve sua última versão em Abril de 2018, quando reuniu um público de 600 pessoas, com a participação de 87 universidades brasileiras e 5 estrangeiras. Foram apresentados 182 artigos científicos, 13 palestras 1 oficina e 3 mesas-redondas.

Palavras-chave: Sustentabilidade. Evento de Extensão. Interdisciplinaridade.

\section{UNIVERSITY EXTENSION APPLIED AS INTEGRATED RESEARCH AND UNIVERSITY EDUCATION THROUGH ENSUS MEETING}

\begin{abstract}
ENSUS - Project Sustainability Meeting is an annual national event. It lasts for three days. It happens in Florianópolis, UFSC - Federal University of Santa Catarina. It is the main event of a university extension program that encompasses several activities. The main objective is to promote the dissemination of knowledge generated in research, with the theme of sustainability applied in projects. It has for target audience, undergraduate and graduate students. It also attracts researchers and practitioners from these areas. It is interdisciplinary, favors the exchange of theoretical and practical experiences between Brazilian and foreign universities. I had last version in April of 2018, when gathered a public of 600 people, with the participation of 87 brazilian universities and 5 foreign universities, with 182 scientific articles, 13 lectures ,1 office labor and 3 roundtables.
\end{abstract}

Keywords: Sustainability. Extension Event. Interdisciplinarity.

\section{APLICACIÓN DE LA EXTENSIÓN COMO ELO ENTRE LA INVESTIGACIÓN Y LA ENSEÑANZA UNIVERSITARIA A TRAVÉS DEL CONGRESO ENSUS}

\section{Resumen}

El ENSUS - Encuentro de Sustentabilidad en Proyecto es un evento anual, con una duración de tres días, que se realiza en la ciudad de Florianópolis (SC), en el campus de la UFSC - Universidad Federal de Santa Catarina. Es la principal actividad de un programa de extensión universitaria que engloba diversas otras actividades, cuyo objetivo principal es promover la diseminación del conocimiento generado en investigaciones con la temática de la sustentabilidad aplicada en proyectos, enfocada en ingeniería, arquitectura y diseño. Tiene por público objetivo, estudiantes de graduación y postgrado, además de investigadores y profesionales actuantes de estas áreas. Es por esencia interdisciplinaria, fomentando el intercambio de experiencias teóricas y prácticas entre universidades brasileñas y extranjeras. Tuvo su última versión en abril de 2018, cuando reunió a un público de 600 personas, con la participación de 87 universidades brasileñas y 5 extranjeras. Se presentaron 182 artículos científicos, 13 conferencias 1 taller y 3 mesas redondas.

Palavras clave: Sostenibilidad. Evento de Extensión. Interdisciplinariedad. 


\section{INTRODUÇÃO}

Este artigo relata um conjunto de atividades realizadas na Universidade Federal de Santa Catarina (UFSC) pelo grupo de pesquisa Virtuhab, no laboratório MATEC, que objetivam disseminar o conhecimento da sustentabilidade para o público-projetista e seus clientes, mediante ações de educação ambiental que incluem a editoração de um periódico científico (MIX Sustentável), programas de educação/informação ambiental mediante projetos de pesquisa e extensão (Materioteca Sustentável, Usos do Bambu, Permacultura, etc.) e que culminam na realização do congresso ENSUS - Encontro Nacional de Sustentabilidade Aplicada em Projetos.

A sustentabilidade é um dos assuntos mais discutidos atualmente e envolve as mais diversas áreas do conhecimento: das ciências sociais aplicadas às engenharias, passando pelas ciências humanas, exatas, etc.. No aspecto profissional, espera-se que todos estejam cientes e atualizados estar ciente e atualizado sobre o tema. . Nos dias de hoje, cada pessoa deve ser capaz de reconhecer sua parcela de responsabilidade no mundo moderno, do que pode fazer para contribuir com a sustentabilidade, independente do tipo de atividade profissional exercida. A sustentabilidade neste aspecto atua como um elo social, no qual cada ação individual tem efeito compartilhado por todos.

Hansen e outros (2010) explicam que a conscientização da sociedade por um desenvolvimento sustentável uniu-se à busca pelo aumento do desempenho ambiental das organizações. Isso estimulou a evolução de uma nova linha de pensamento que prima avaliar o saldo ambiental de produtos e serviços, por meio de uma abordagem ampla das inter-relações entre os sistemas e o meio ambiente. Passou a ser conhecida por Avaliação do Ciclo de Vida (ACV) e é aplicada muitos vezes de forma específica: ciclo de vida de materiais; ciclo de vida do processo produtivo; ciclo de vida da cadeia produtiva, e assim por diante.

Tanto no meio acadêmico quanto no industrial, o tema "sustentabilidade" tem sido inserido gradualmente. É difícil encontrar no mercado algum evento (capacitações, treinamentos, programas de pós-graduação, cursos de aperfeiçoamento, palestras, simpósios, feiras, etc.) que não inclua a questão da sustentabilidade como foco de discussão. Outra constatação que comprova o aumento do interesse do tema é na quantidade de artigos enviados aos congressos, eventos e periódicos, onde a área da sustentabilidade teve acréscimo considerável nas publicações. Contudo, apesar desse aumento, a compreensão necessária do tema ainda esbarra em dois aspectos interligados: a complexidade dos fatores envolvidos, e o desconhecimento das variáveis e condicionantes interligados. 
Conforme destacam Kubota e outros (2014), a maioria dos artigos encontrados na área ambiental (63\%) ainda são de caráter predominantemente teórico, onde se propõe métodos e modelos conceituais de desenvolvimento de produtos, considerando aspectos de projeto técnico alinhados a aspectos do ecodesign, por vezes denominado design sustentável. A maior parte deles apresentam estudo de casos para a avaliação dos modelos propostos. Há, portanto, carência de abordagens e aplicações práticas, preferencialmente sob a forma de extensão universitária, fortalecendo o vínculo pesquisa - ensino - extensão.

O tema "sustentabilidade", mesmo inserido em vários eventos científicos, encontra-se diluído em diversas linhas de pesquisa; existindo poucos eventos como o mostrado nesse artigo, que correlaciona a sustentabilidade com o projeto de produtos como tema principal, e que reúna, em só local, atividades que interessem aos diferentes públicos que precisam entender a relação sustentabilidade x projeto (estudantes de graduação, pós-graduação, estudantes de ensino médio, profissionais do mercado, público em geral).

O ENSUS reúne, em um só evento, apresentação de artigos científicos, mini-cursos, palestras técnicas, oficinas práticas e concursos. Tanto o congresso quanto as demais ações de extensão correlatas, como a editoração do periódico Mix Sustentável e oferta de workshops (dentre outras), envolvem principalmente estudantes das áreas relacionadas a atividades de projeto de produto, como engenharia, arquitetura e urbanismo e design. O evento também conta com palestrantes nacionais e estrangeiros, mesas-redondas, oficinas práticas e exposições de projetos e produtos de universidades, órgãos diversos e universidades.

O periódico Mix Sustentável tem duas edições regulares por ano, além de edições especiais, em geral duas por ano também. Uma destas edições é sempre vinculada ao ENSUS e publica versões ampliadas dos melhores artigos apresentados no evento. O periódico possuiu quatro sessões: (1) artigos científicos; (2) entrevistas com profissionais da área; (3) resumos de TCC - Trabalhos de Conclusão de Curso de graduação, e (4) resumos de trabalhos finais de pósgraduação. Este artigo tem por objetivo mostrar a relação existente entre as ações de extensão ENSUS e Mix Sustentável com o ensino e a pesquisa, mantendo um vínculo e um correlacionamento constante.

\section{HISTÓRIO DO EVENTO E DA REVISTA}

O ENSUS é a atividade principal do programa de extensão aqui demonstrado e abrange as áreas de ciências sociais aplicadas e ciências exatas, agrárias e das engenharias. A demanda a ser atendida é de profissionais que tenham a sustentabilidade como foco, envolvendo pesquisadores 
da área projetual, profissionais do mercado, estudantes dos mais variados níveis e público em geral. A característica básica do público-alvo é o interesse em relacionar e aplicar a sustentabilidade sob o enfoque econômico, social e ambiental em seus projetos, específicos para cada área.

As primeiras três edições do ENSUS aconteceram no campus da Univali - Universidade do Vale do Itajaí, nos anos de 2007 a 2009, encerrando um triênio de experimentação. Após um período sem ocorrer, no ano de 2016 o evento voltou a acontecer, desta vez, na UFSC Universidade Federal de Santa Catarina.

Integrando desde o primeiro momento as atividades de pesquisa e extensão, um dos primeiros trabalhos realizados pelos alunos bolsistas foi o desenvolvimento da logomarca do evento, que se manteve inalterada após seu registro. Os alunos participaram não somente da elaboração da marca do evento, também elaboraram todo o manual da marca, necessário para registro. A figura 1 mostra a logomarca, na versão do evento deste ano e na versão com a inclusão da data do evento de 2019 elaborada para divulgação em página web como facebook.

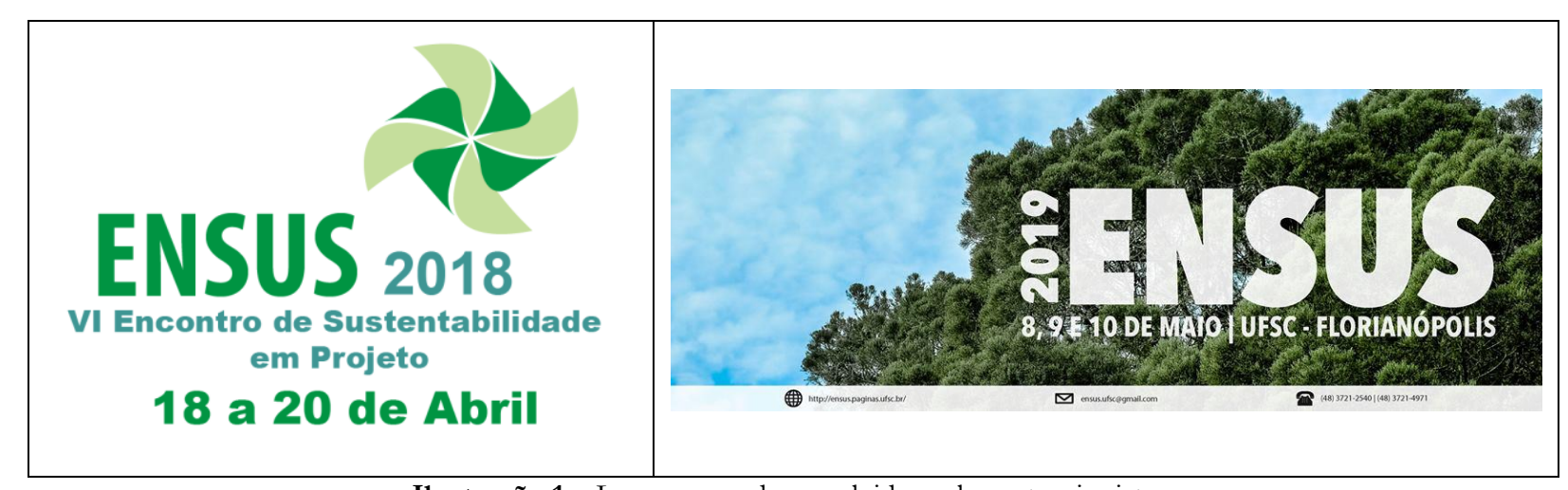

Ilustração 1 - Logomarcas desenvolvidas pelos extensionistas.

Fonte: própria.

Como parte integrante do projeto, a revista Mix Sustentável teve sua origem no ENSUS de 2008, quando publicou os melhores artigos do evento. Denominada na ocasião de MIG Revista Científica do Design, teve a segunda edição no ENSUS 2009, mas não teve na época continuação e não apresentou número regulares. No ano de 2015, já prevendo a retomada do ENSUS, e com alteração na equipe de editoração, ISSN e universidade sede, foi lançado o periódico MIX Sustentável, com objetivo de ser regular, com edições especiais do ENSUS.

Com vistas à integração da extensão também como potencial aprendizagem acadêmica, todo o trabalho de editoração fica a cargo de alunos extensionistas. Durante o período do lançamento da revista, (volume 1 n. 1 em outubro de 2015), cujo trabalho de preparação iniciouse com o projeto de extensão do programa Pro-bolsas denominado "Mix Sustentável”, de Março 
de 2015 até o momento, nove bolsistas de extensão do curso de Design Gráfico trabalharam na editoração do periódico, formatando artigos, criando os templates, capas, etc.. A figura 2 ilustra as edições lançadas até o momento.

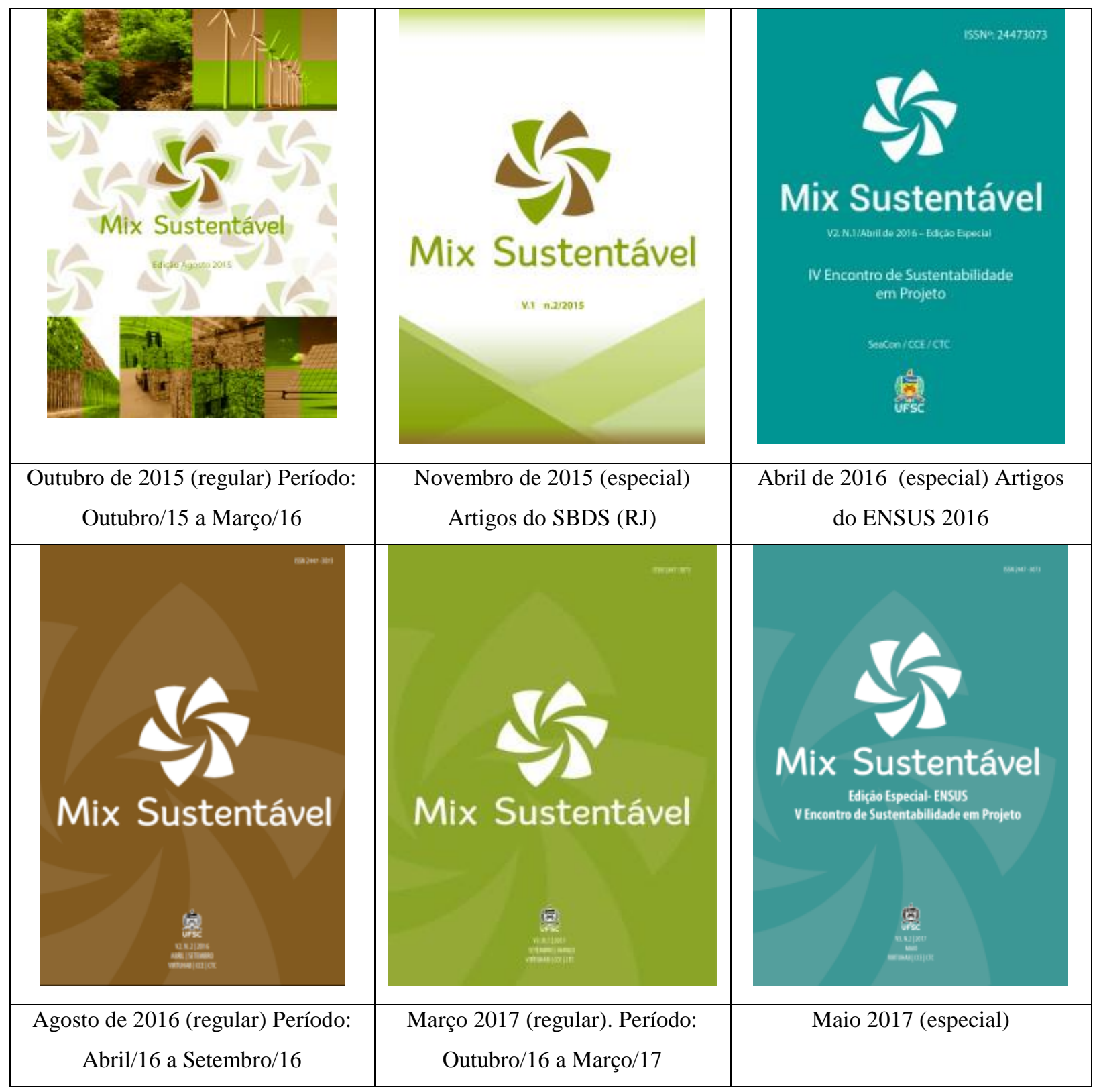




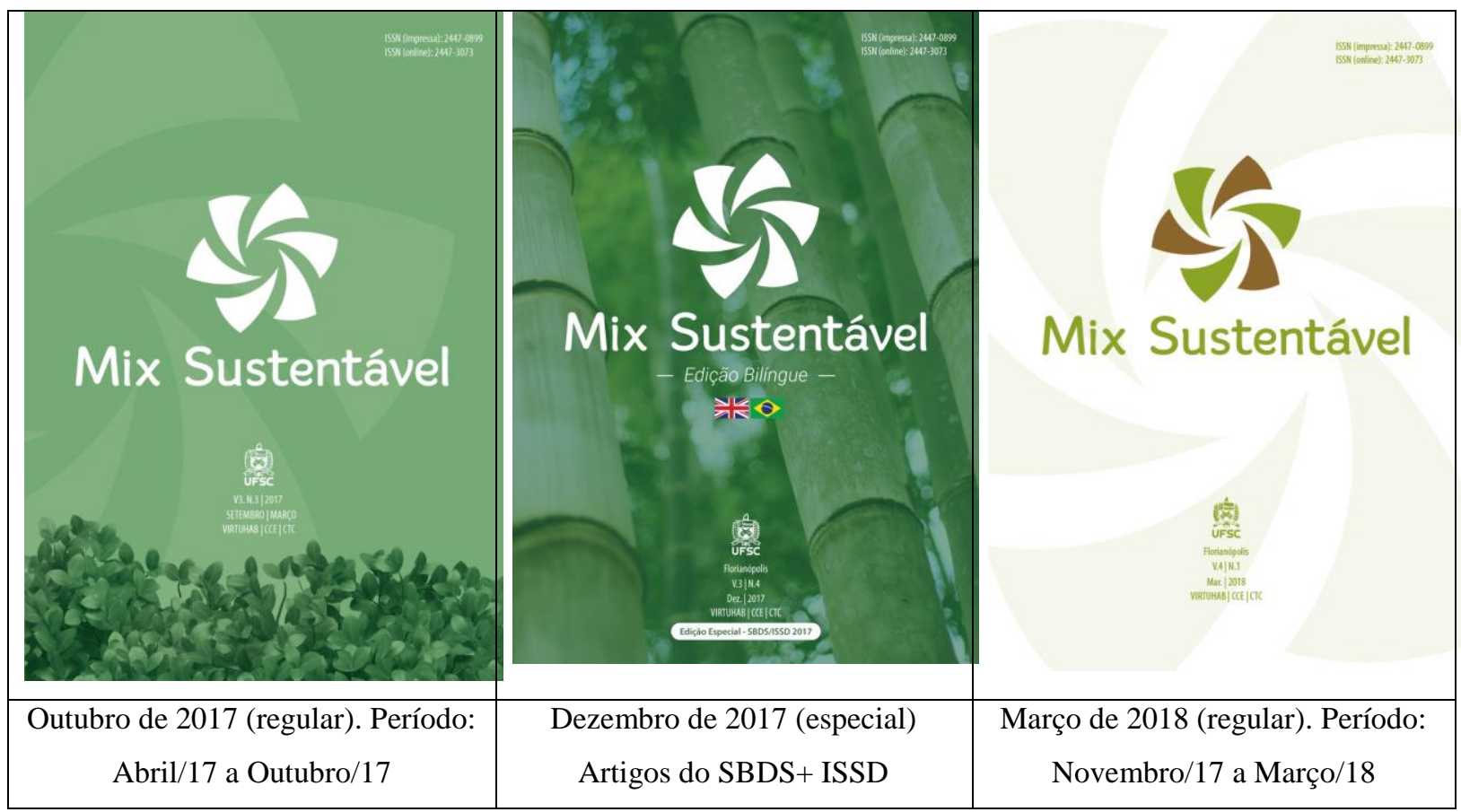

Ilustração 2 - Capas das edições da Mix Sustentável lançadas até o momento. Fonte: própria.

Os preparativos para o ENSUS 2019 já estão em andamento, com os alunos extensionistas mantendo atualizadas as páginas do evento que aconteceu no corrente ano, bem como iniciando os contatos com possíveis palestrantes e expositores para o evento de 2019. O cronograma prevê o lançamento da chamada para envio de artigos para o evento para o mês de setembro de 2018, e por isso os alunos também estão preparando material de divulgação. O site do ENSUS, bem como sua página de facebook, também está em constante atualização por alunos da extensão. A figura 3 ilustra alguns trabalhos gráficos realizados por alunos extensionistas para divulgação das atividades do evento. 
Aplicação da extensão como elo entre a pesquisa e o ensino universitário através do congresso ENSUS

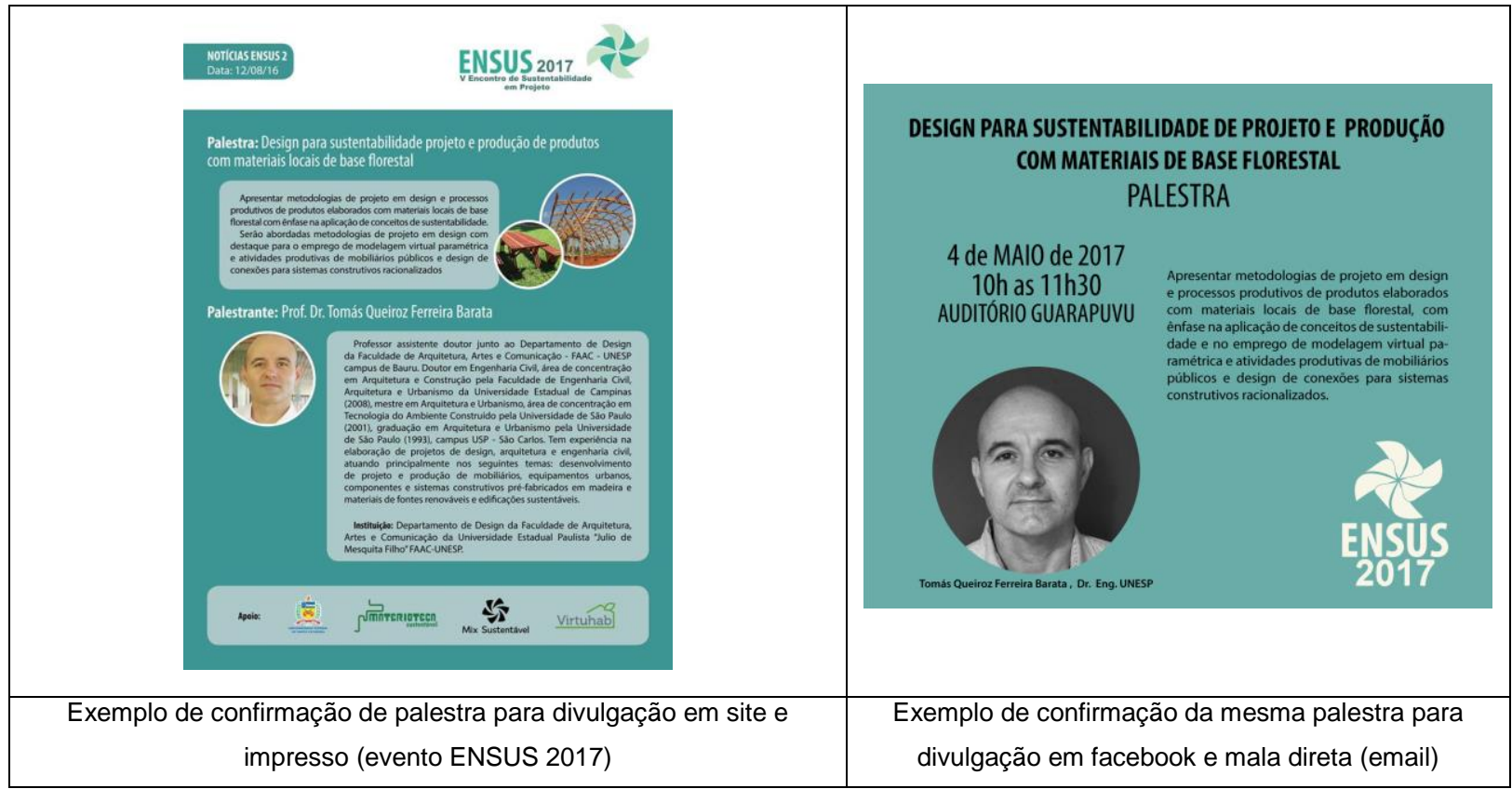




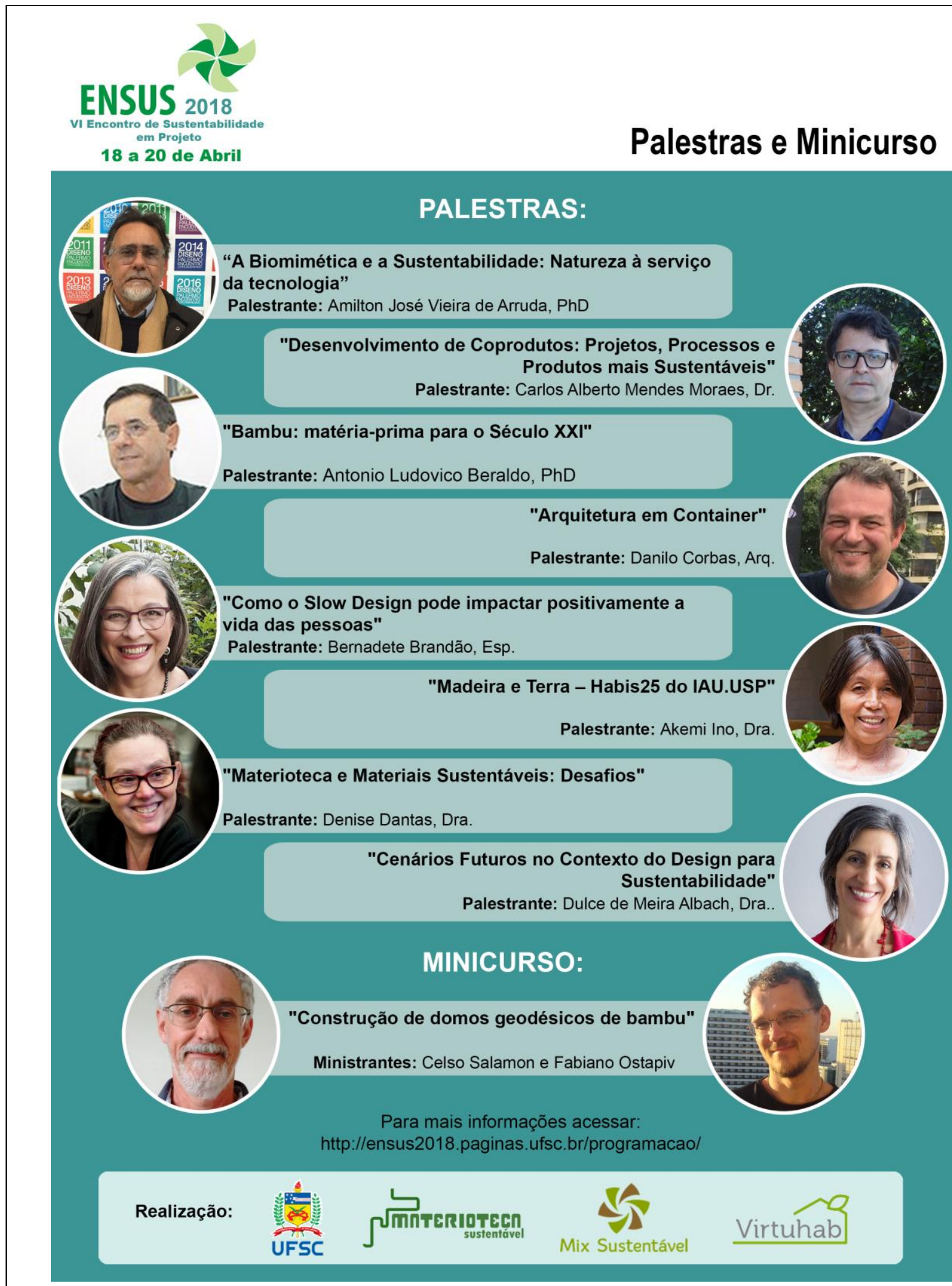

Exemplo de divulgação geral das palestras para impressão em formato A3 - evento ENSUS 2018

Ilustração 3 - Trabalhos gráficos realizados pelos alunos da extensão.

Fonte: própria. 
De acordo com a mídia escolhida (site, mala direta por email, facebook, impresso, etc.) a abordagem gráfica é diferenciada. Os alunos realizam painéis semânticos e pesquisa de tendências e público-alvo no sentido de definir a abordagem gráfica que será usada para as divulgações, escolhendo o melhor padrão gráfico para cada mídia. Ou seja, a mesma palestra, por exemplo, tem diferentes versões: versão para impressão, versão para facebook, versão para página web, versão para mala direta via e-mails, etc..

\section{ATIVIDADES DE EXTENSÃO PRÉ E PÓS-ENSUS}

Sendo o ENSUS e a revista Mix Sustentável as atividades principais do programa de extensão denominado "Ações integradas culturais: extensão e pesquisa aplicadas em sustentabilidade", em andamento desde 2013, diversas ações de extensão são realizadas pré e pósensus, no intuito tanto de tornar conhecido o evento atraindo público, bem como demonstrar todo o conhecimento gerado nas edições anteriores.

Uma das ações é a materioteca de produtos sustentáveis. A "MATERIOTECA" Com Ênfase na Sustentabilidade - Uma Nova Abordagem para Seleção de Materiais Aplicados ao Projeto é uma proposta que tem por objetivo viabilizar uma análise da sustentabilidade (social, econômica e ambiental) nos diversos materiais utilizados em projeto de produtos.

Em processo contínuo de montagem (pela aquisição de novos materiais e elaboração de fichas dos já disponíveis), a materioteca está localizada no campus da UFSC, no departamento de Arquitetura e Urbanismo, junto ao Virtuhab, com livre acesso aos estudantes, especialmente das áreas relacionadas a atividades de projeto de produto, como engenharias (civil, mecânica, de produção, elétrica, etc.), arquitetura e urbanismo e design de produto.

Pelo aspecto pretendido, o principal objetivo da materioteca é preencher uma lacuna existente nas atuais materiotecas, ao proporcionar que o usuário tenha, além de amostras e relatórios contendo propriedades, características, exemplos de aplicação, demonstrações, etc.. (comuns as todas as materiotecas) a análise da sustentabilidade do referido material, em comparação aos demais materiais diretamente concorrentes para cada aplicação em específico. Essa análise contempla os aspectos sociais, econômicos e ambientais.

As atividades relacionadas à materioteca integram a pesquisa de novos materiais e novos processos fabris, catalogação dos já existentes, desenvolvimento das fichas catalográficas com ciclo de vida de cada material, etc.. Os extensionistas também participam de atividades de exposição de materiais (em feiras e eventos) e visitas a escolas, objetivando a iniciação em 
materiais para os jovens estudantes, dando ênfase nas questões ambientais de cada material, como degradação, consumo de energia, possibilidades de reciclagem e reaproveitamento, entre outros.

O projeto da materioteca iniciou-se em 2013, através do programa do PROEXT Programa de extensão universitária MEC/SESu. Com o recurso do referido edital, os alunos do curso de Design e do curso de Arquitetura desenvolveram a logomarca da materioteca, criaram o site, templates para as fichas de cada material, template para o ciclo de vida de cada material e projetaram um dos móveis para exposição dos materiais. Após este primeiro projeto, a continuidade deu-se através dos editais internos de extensão mediante o programa Probolsas da UFSC. A partir de então os alunos passaram a se envolver também com outras atividades do projeto, como as visitas e exposições. A figura 4 mostra a marca desenvolvida pelos alunos do curso de design e um dos modelos usados para catalogação no site (fichas técnicas).

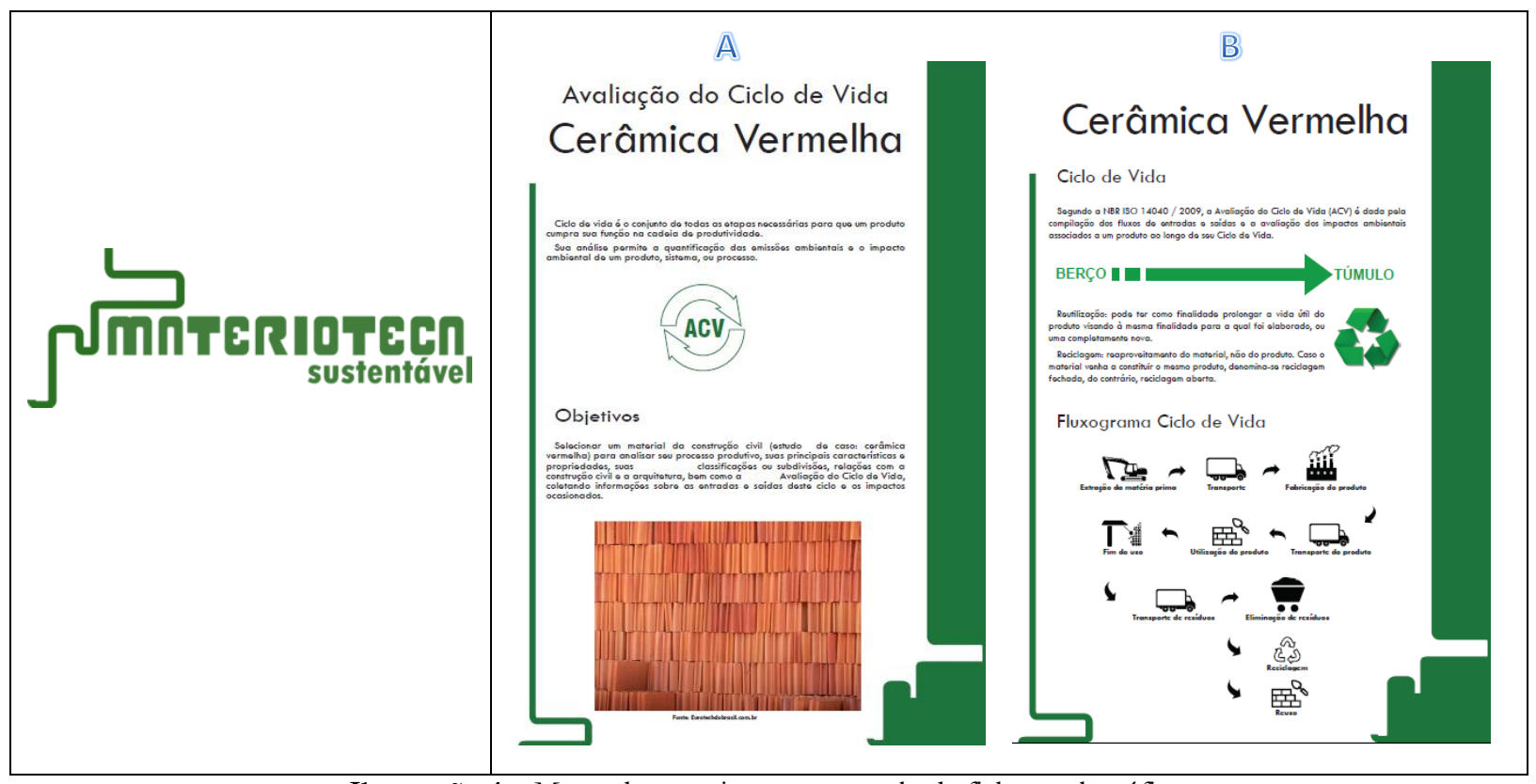

Ilustração 4 - Marca da materioteca e exemplo de ficha catalográfica. Fonte: própria.

Conforme comentam Ashby e Johnson (2011), a classificação é a primeira etapa para trazer ordem a qualquer empreendimento científico; ela segrega uma população inicialmente desordenada em grupos que, de algum modo, possuem semelhanças significativas. Em virtude do projeto de produtos ser uma atividade multidisciplinar em essência, a classificação desempenha um papel muito importante. "Projeto envolve escolha, e uma escolha é feita a partir de uma enorme gama de idéias e dados - entre eles, a escolha de materiais e processos" (ASHBY; JOHNSON, 2001, p. 123). Logo, é essencial na área de materiais e processos que a classificação 
ocorra por intermédio de uma materioteca, ponto de partida para análises mais aprofundadas, como, por exemplo, o desempenho em nível de sustentabilidade comparativo entre materiais.

Como se observa na figura 5, usada para exemplificação, as amostras de madeiras possuem todas o mesmo tamanho (perímetro e espessura). Quando possível, as amostras de materiais pertencentes a outros grupos também foram fabricadas com as mesmas medidas (comprimento, largura e espessura). A uniformidade física facilita observações por parte do usuário, como por exemplo, o peso relativo entre um tipo de material e outro. A parte A da figura 2 mostra diversos tipos diferentes de madeiras naturais e transformadas. O estudante pode, pela simples experimentação tátil, comparar características próprias de cada material, como peso relativo, textura, cor, dureza superficial, e outros. No caso mostrado na parte B da figura 5, verifica-se outra vantagem, como a possibilidade de comparação entre a seção transversal de materiais diversos. No caso específico do exemplo, temos amostras de madeira natural Teca, madeira transformada compensada laminada, madeira transformada compensada sarrafiada, madeira natural Cinamomo, madeira transformada do tipo MDF, madeira transformada do tipo OSB e material natural: bambu.

\section{A - Tamanho padrão escolhido para as amostras de madeiras.}

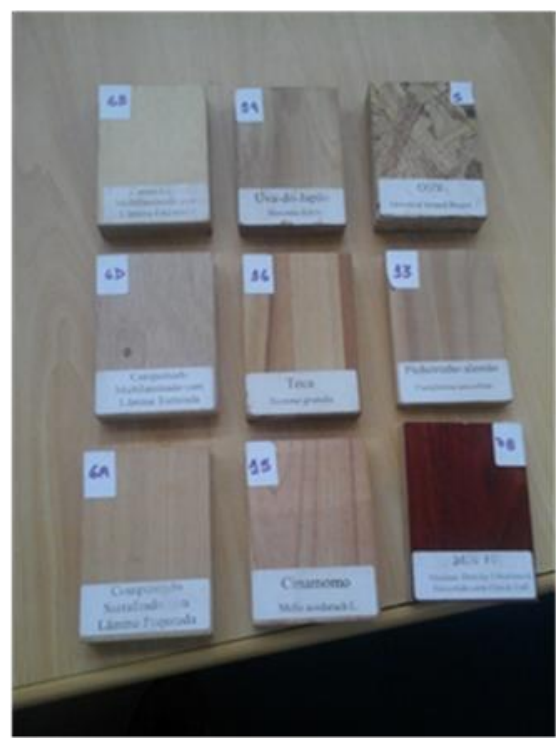

Ilustração 5 - Amostras da materioteca. Exemplos. Fonte: própria.

\section{B - Seção transversal, em ordem: Teca, Compensado laminado, Compensado sarrafiado, Cinamomo, MDF, OSB e Bambu.}

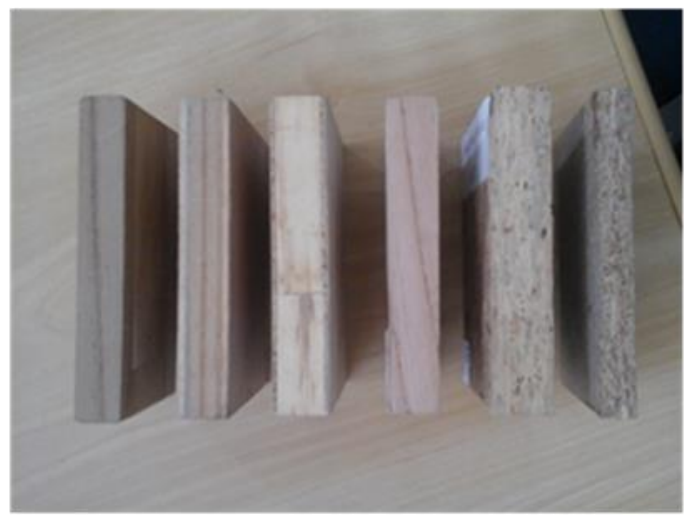

De acordo com os objetivos traçados, os alunos extensionistas que participam do projeto envolvem-se nas atividades de pesquisa, ensino e extensão. Na parte referente à pesquisa, estes precisam buscar informações atualizadas dos grupos de materiais, novos materiais lançados no 
mercado e novidades mostradas em feiras e eventos. A alimentação contínua do site do projeto: http://materioteca.paginas.ufsc.br é feita pelos alunos da extensão.

Como atividade de extensão os alunos frequentemente visitam escolas, onde mostram amostras e explicam propriedades, características, pontos fortes, limitações e exemplos de uso de cada material. Sempre com ênfase na sustentabilidade, essas visitas têm por principal objetivo a educação e conscientização ambiental das futuras gerações. A figura 6 mostra uma das alunas do projeto em uma das visitas realizadas com este objetivo e a figura 7 mostra alguns momentos onde se fazem exposições da materioteca, em feiras e eventos, como por exemplo, na SEPEX Semana de Ensino, Pesquisa e Extensão da UFSC.

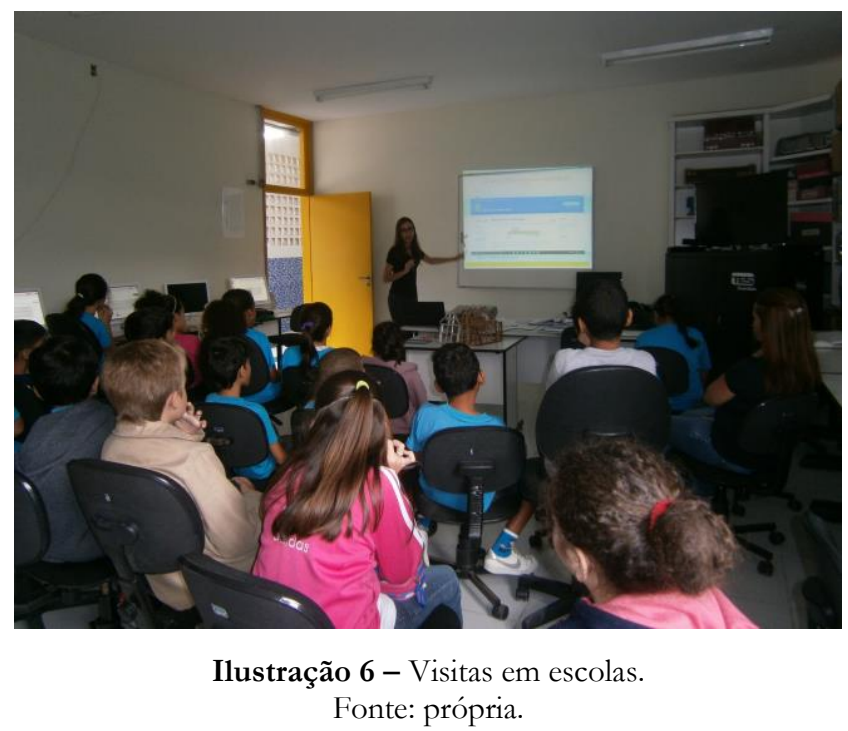

Nestas exposições, os alunos bolsistas explicam o funcionamento do site, especialmente no que diz respeito à seleção de materiais por meio das fichas online e utilizando-se dos quadros disponibilizados que integram o modelo ESA (LIBRELOT'TO, 2009), que avalia a sustentabilidade nos critérios sociais, econômicos e ambientais com o método MAEM-6F (FERROLI, 2009), que conduz a escolha de materiais através da análise dos fatores fabris, econômicos, mercadológicos, ecológicos, ergonômicos e estéticos.

Outras ações de extensão desenvolvidas pelo programa de extensão são workshops de temas variados, sempre com temática ambiental. Os worskshops são criados como ações de extensão que objetivam demonstrar, mediante oficinas práticas, o uso de materiais alternativos e projetos, voltados para arquitetura, engenharia ou design. Até o momento foram realizados dois workshops, que contaram com a participação de um instrutor externo à universidade.

O primeiro foi uma oficina para confecção de poltrona e estrela de geodésica em tubos de papelão. $\mathrm{Na}$ etapa de planejamento da atividade foram realizados os projetos, estabelecidas as medidas e quantidades de materiais necessários. Os desenhos da oficina foram realizados por 
alunos extensionistas da arquitetura orientados por mestrandas do PósARQ da UFSC. A figura 8 ilustra algumas etapas do projeto.

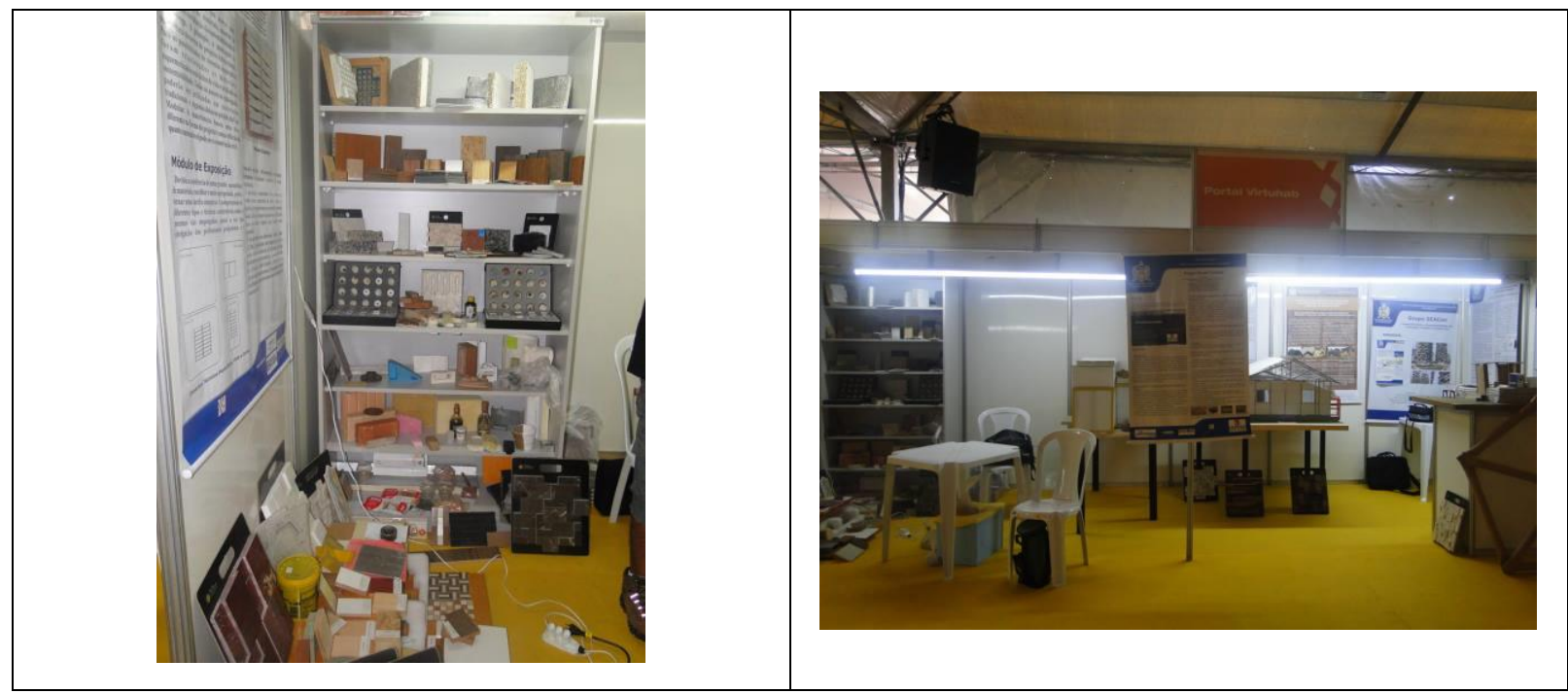

Ilustração 7 - Atividade de extensão - exposição de materiais. Fonte: própria.

$\mathrm{Na}$ primeira parte da figura 8 apresenta-se o projeto. $\mathrm{Na}$ segunda ilustração, uma das etapas construtivas, mostrando com detalhes o sistema de união entre os tubos de papelão, que foram previamente cortados e furados. Na terceira ilustração, montagem e explicação das propriedades do material pela instrutora. E na quarta ilustração, projeto da cadeira finalizado.

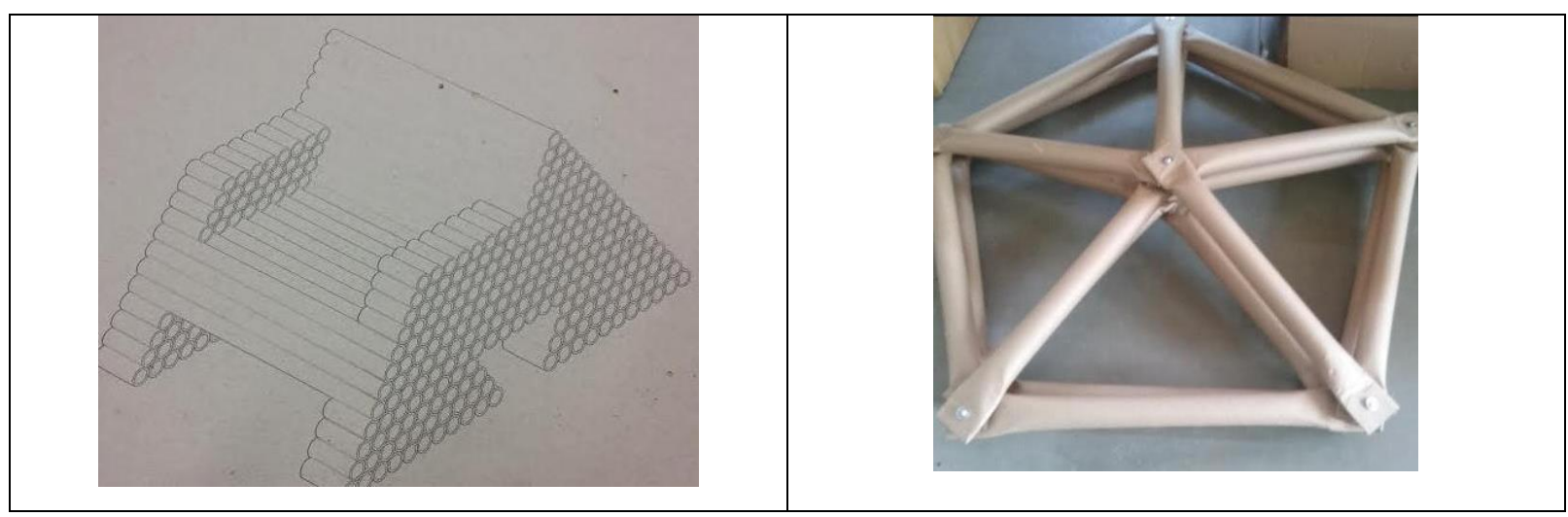




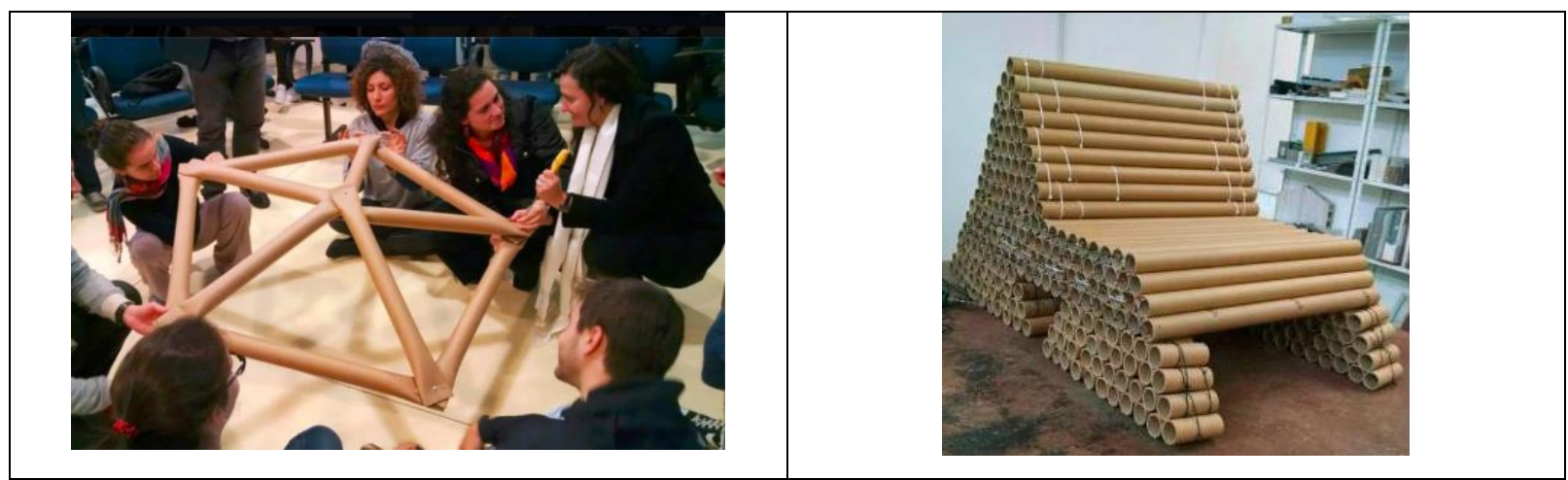

Ilustração 8 - Workshop de projetos com tubos de papelão.

Fonte: Armando, Hoffmann e Librelotto (2015).

O segundo workshop foi a oficina para construção da geodésica e painéis de tubos de papelão. A geodésica construída pode ser considerada como de menor complexidade. Os tubos de papelão, após coletados, foram cortados nas medidas especificadas. Após foram montadas as seis estrelas necessárias passa-se a montagem da geodésica, iniciando da base para o topo. Conforme Salado (2013), os tubos foram unidos por barras roscadas. A figura 9 ilustra algumas etapas da confecção do painel e da geodésica.

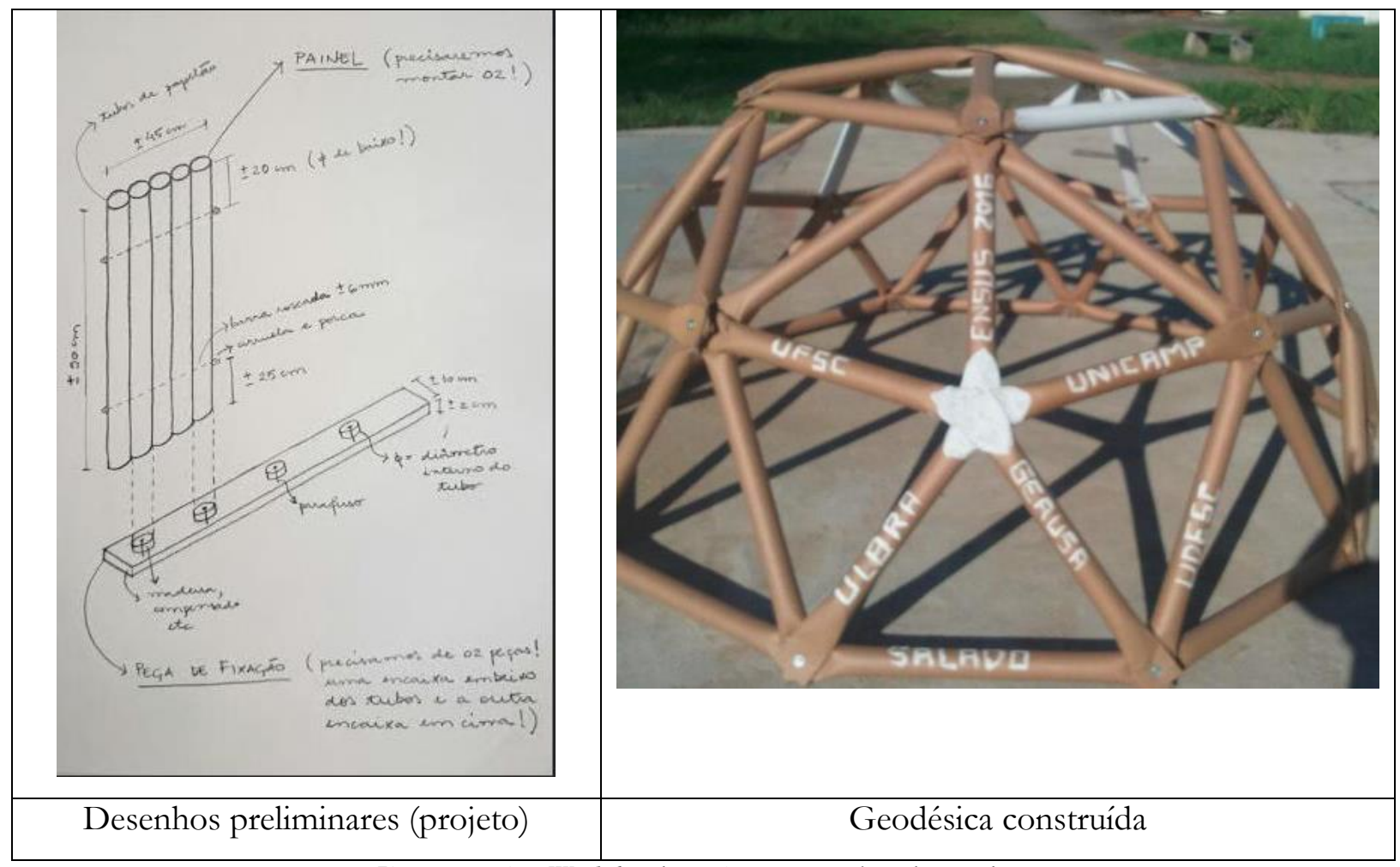

Ilustração 9 - Workshop de projetos com tubos de papelão.

Fonte: Salado (2011)

No total, somando-se as duas oficinas, cerca de 60 pessoas tiveram envolvimento direto na atividade. O esforço da realização da atividade traz como benefícios: divulgação da 
importância de se repensar a forma como se projeta, como se emprega os materiais e sobretudo, de como se percebe o descarte de materiais que podem agregar valor em outros usos. A escolha do foco da oficina também é essencial, pois a prática está pautada em trabalho com respaldo técnico, de um arquiteto mundialmente reconhecido, como o Shigeru Ban (BAN, 2016), e no desenvolvimento tecnológico de materiais alternativos testados em laboratório, como o da professora. Gerusa Salado. Destaca-se a importância da integração no tripé ensino - pesquisa extensão, com a participação e envolvimento de alunos da graduação, pós-graduação e da comunidade externa.

\section{ENSUS 2018 - INÍCIO DA INTERNACIONALIZAÇÃO DO EVENTO}

No evento deste ano, manteve-se a mesma estrutura que nos anteriores; contudo, o recebimento de artigos foi dividido em nacional e internacional. Desta forma, foram criadas duas sessões temáticas especiais para os autores que submeteram seus trabalhos em língua estrangeira (inglês ou espanhol). Além da apresentação dos artigos em língua estrangeira, estes também foram divididos nos anais do evento. Todo sistema foi gerenciado pelo easychair, conforme ilustra a figura 10.

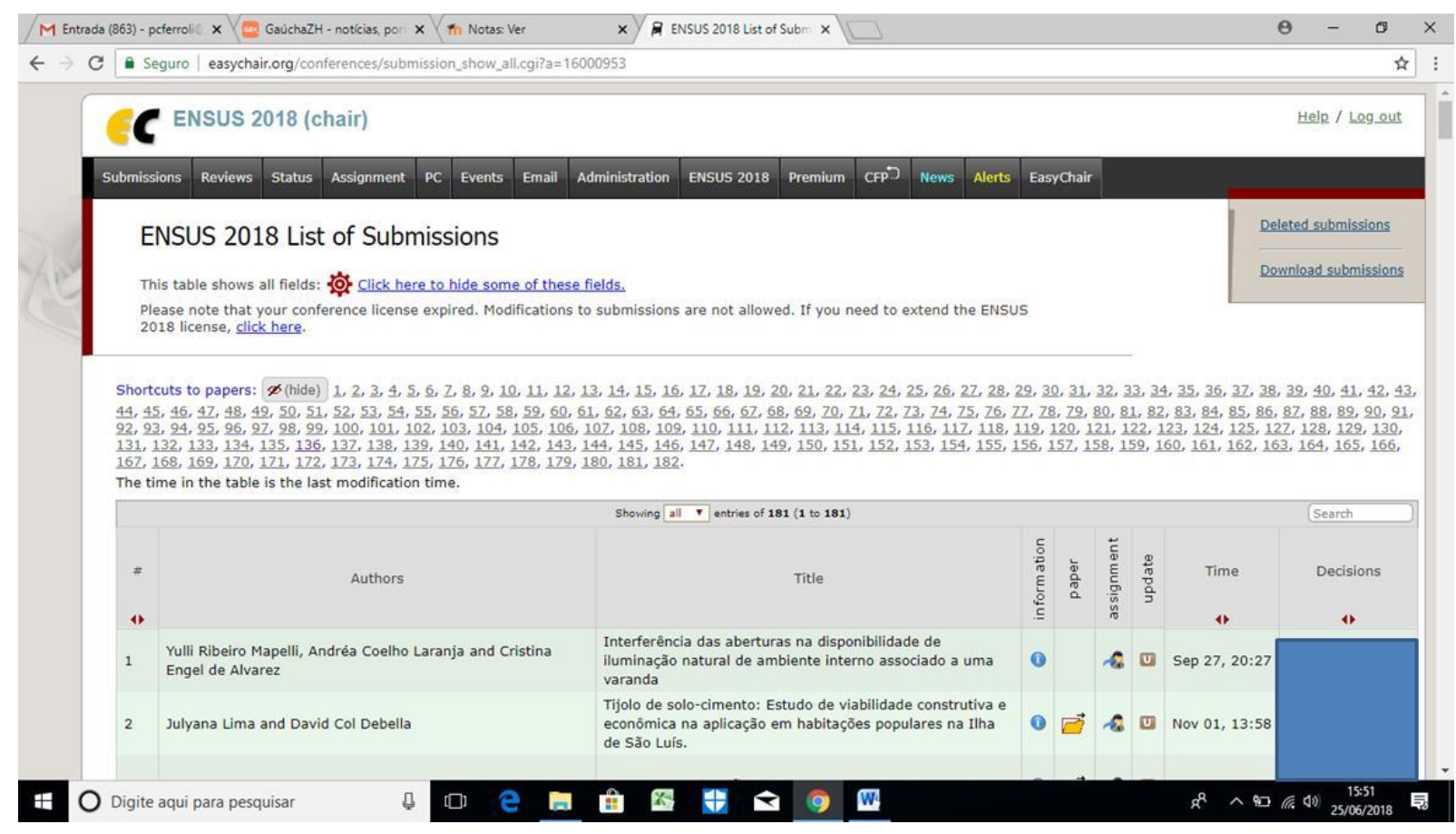

Ilustração 10 - Gerenciamento dos artigos enviados ao evento ENSUS 2018.

Fonte: https://easychair.org/conferences/submission_show_all.cgi?a=16000953 
A figura 11 mostra alguns momentos do evento de 2018, que contou com vários expositores, dentre os quais carro elétrico, projetos de design do PRONTO 3D, oficina de construções em bambu, bicicleta em bambu, móveis realizados com sobras de materiais de construção civil, fogão elétrico, etc.. Ao todo participaram do evento representantes de 76 universidades públicas e privadas, do Brasil e de outros países.

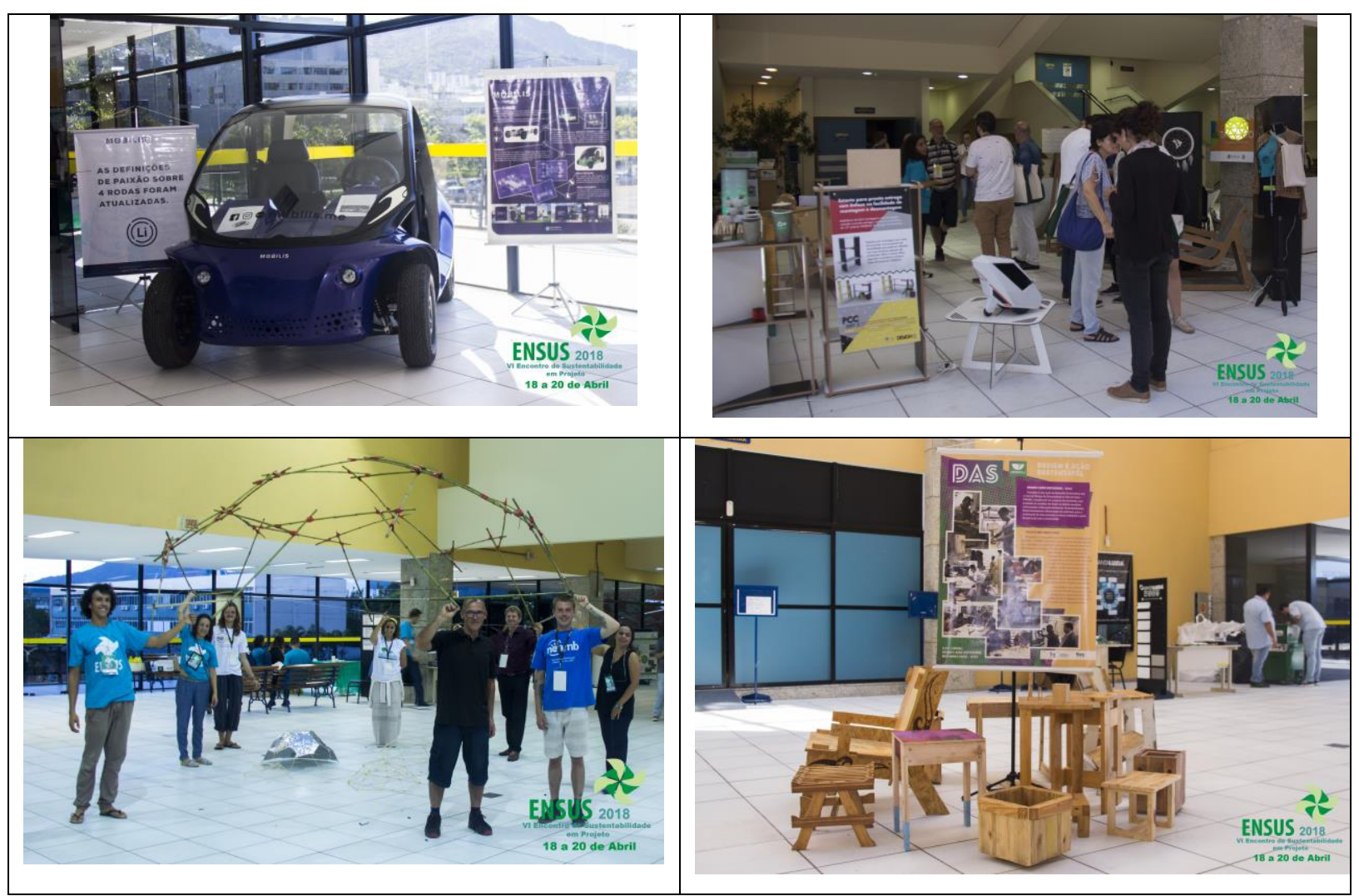

Ilustração 10 - Algumas atividades do ENSUS 2018.

Fonte: http://ensus2018.paginas.ufsc.br/

\section{CONSIDERAÇÕES FINAIS}

É consenso que o projeto englobando os preceitos da sustentabilidade é a solução para que se alie a melhoria contínua à necessidade cada vez maior da preservação dos recursos naturais, qualidade de vida do homem, ao capitalismo vigente. A difusão de pesquisas e ações de extensão universitária que tem criado tecnologias menos degradantes, na dimensão ambiental; mais econômicas e que ajudam a demover injustiças sociais a muito estabelecidas no país é de extrema importância para o alcance do desenvolvimento sustentável. São exemplos os aquecedores solares e lâmpadas com garrafas PET, sistemas construtivos e componentes para habitação de material reciclado ou que reaproveitam resíduos, biodigestores, entre outros. 
Aplicação da extensão como elo entre a pesquisa e o ensino universitário através do congresso ENSUS

É certo que a discussão da sustentabilidade, no que se refere às dimensões Econômica, Social e Ambiental - ESA (LIBRELOTTO, 2009) não deve estar restrita ao ambiente acadêmico e deve incluir o mercado de trabalho (empresas e profissionais). Deve integrar o campo das ideias ao material, dando oportunidade para a prática e o experimento.

Este artigo apresentou um conjunto de ações de extensão desenvolvidas ao longo dos últimos seis anos pelo laboratório Virtuhab. Em constante atualização, os projetos mostram a interligação existente entre o evento ENSUS, a revista Mix Sustentável, a Materioteca e os diversos workshops práticos onde os alunos bolsistas precisam aliar pesquisa e extensão no cumprimento de suas tarefas.

Outro fator importante é a interdisciplinaridade favorecida pelo projeto, pois este envolve alunos tanto de graduação quanto de pós-graduação, de diversos cursos da universidade.

\section{REFERÊNCIAS}

ARMANDO, Clarissa; HOFFMANN, Aniara e LIBRELOTTO, Lisiane Ilha. Fotos e materiais oficina arquitetura e design com tubos de papelão. Florianópolis, UFSC, 2015.

ASHBY, Michael; JOHNSON, Kara. Materiais e Design. Rio de Janeiro: Campus, 2011.

BAN, Shigeru. Architects (2016). Disponível em: <http:www.shigerubanarchitects.com>. Acesso: 2016.

HANSE, J., R. RUEDY, M. SATO, N., 2010: Global surface temperature change. Rev. Geophys., 48, RG4004, doi:10.1029/2010RG000345.

\section{LIBRELOTTO, Lisiane Ilha. Modelo para Avaliação de Sustentabilidade na Construção Civil nas Dimensões Econômica, Social e Ambiental (ESA). São Paulo: Blucher, 2009.}

SALADO, GERUSA DE CÁSSIA. Painel de vedação vertical de tubos de papelão: estudo, proposta e análise de desempenho. Tese de doutorado. Escola de Engenharia de São Carlos. USP. São Carlos, São Paulo, 2011.

Recebido em: 19/06/2017

Aceito em: 03/07/2018 